\title{
PLACE AND PERSONAL CIRCUMSTANCES IN A MULTILEVEL ACCOUNT OF WOMEN'S LONG-TERM ILLNESS
}

\author{
R. D. WIGGINS ${ }^{1}$, H. JOSH I, M. BARTLEY ${ }^{2}$, \\ S. GLEAVE, K. LYNCH, and A. CULLIS \\ Centrefor Longtudinal Studies, TheInstitute of Eduration, London, U.K. \\ 1 Also of Department of Socidogy, City Univesity, London, U.K. \\ ${ }^{2}$ Also of Department of Epidemidogy andPublicHe日lth, UnivesityCdlege, \\ London, U.K.
}

\begin{abstract}
A bstract
This paper investigates geographical variations in wamen's reparts of limiting longterm illness in tems of indridual inequalities and the contribution of area dharaderistics among wards and county distrids. We use miltiled moddling of linked census data from the Office for National Statistics Longiudinal Study for England and Wales. Wefdlowa randomsample of 76,374 women aged between 16 and 45 at the time of the 1971 Census for 20 years to dbserve their reported limiting longtemillness (LLTI) at the 1991 Census Car and home ouneship were useful markess of soial and material advantage apparently protetingagainst therisk of reparting LLTI. Migration into theSauth-East region appeered benefiaal, but otherwise there was little difference beween those who moved hame and those who did no. Differences between canty distrids persist after adjustment for individual iramstances (eeluration and ethricity), but almost all of thesedifferences are explained by the scial profile of vards in theseareas Geogaphical differenes
\end{abstract}

* This paper has already been published in Social Säeneand Mediane, special issue, vol. 54, no. 5, March 2002, p. 827-838. 
in LLTI are not, therefare, entirdy explained by the distribution of indridual daraderistics a woman with thesamehistay may face a different nisk of illness in different kinds of aree. For women, thesoial composition of thelocality (using the vard as a proxy) is morerderant than thebroader economic andindustrial dassifcation of the sumanding canty distrid, which is more impatant for hellth ine qualities amminmen

Keyw ords: Womer's helth, Geogaphical differeness Limitinglongtemillness, Multilad moddling ONS Longturimal Study.

\section{Résumé}

Les auterrs examinent les variations géogaphiques des délarations demala des invalidantes delongre durée (MLD) dhe les fermes, en temes dinéoglités au niveau individud e de caractéistiques locales au niveau des localités e des dis trids Ils appliquent un modemilti-niveatux aux donnés censitaires appaniés de l'Étude longitudimale menée en Angetere \& au pays de Galles par l'Office for National Statistics On a suivi pendant 20 ans un éhantilllon aléitairede76 374 fermes âgés de 16 à 45 ans au momett du reensement de 1971, afin d'dbserver lems dédarations de MLD au reensenent de 1991. Être propiéaire de son logement e posséder uneviture sont debons indicaterrs dume situation soiale et matéidle confotable qui sombleprotéger contrelensque de délarer uneMILD. Miger ves lesudect du pays parait êreun Aénent favorable mais à part cda, il y a peu de difféence entre migrants et sédentaires. Les difféences entre distrids subsistent une fais que l'on a contrốe les caratéistiques individudles (nivearu dinstruction et arigine thrique, mis dles sont presque tates expliqués par le profil soial des localités dans ces diveses zones. Les difféenes géographiques de délaration des MLD nesont donc pas entièemett imputables à la répartition des caratéistiques indridudles; à partir dela mêmehistare pessonndle, uneferme patt faire face à des nisques de maladie difféents dans des zones géographiques difféentes Parr les fermes, la configration soiale dela localité et plus déteminante que les grandes caradtéistiques économiques \& industridles du distric qui l'enironne, tandis queledistrid jare un rôleplus impatant dans l'explication des difféereses desantéder les hommes

Mots-clés : Santédes fermses Difféences spatiales, Maladie invalidantedelongreduréé, Modëes milti-niveaux, Étudelong̈tudinaledel'ONS. 


\section{Introduction}

Existing research on the social patterning of women's health draws attention to the significance of social roles and socioeconomic position (Arber, 1997; Macintyre and Hunt, 1997). This paper approaches the less well explored question of geographical variations in women's health. It asks what role may be played by geographical variations beyond differing social composition and economic structure. It draws on recent conceptual frameworks, which emphasise the role of area in understanding health inequalities (Arber, 2000; Curtis and ReesJones, 1998; Macintyre \& al., 1993; Moss, this volume). We explore women's health inequalities in England and Wales at two levels of geographical aggregation.

In the examination of area based inequalities in health, it is conventional to distinguish between 'contextual' and 'compositional' factors (Reijneveld and Schene, 1998). Area composition comprises those characteristics, which are the product of the aggregation of individual residents. A good example is the 'deprivation score', derived from the numbers of individuals in an area who are in a disadvantaged social class, unemployed, without cars, living in council accommodation and so on. Area context can be seen from several perspectives. In some work, context is conceptualised as an emergent property of the aggregation of individual characteristics. Although data on the individuals may guard against committing the 'ecological fallacy' (Robinson, 1950), Curtis and Rees-Jones (1998) warn against the risk of committing an 'atomistic fallacy' where the collectivity is more than the sum of its parts. 'Non-deprived' individuals have, for example, been found to have a higher risk of illness in areas where large numbers of 'deprived' persons live (Shouls \& al., 1996). Sloggett and Joshi (1998b) report a similar finding for housewives but not employed women nor men.

O ther studies regard context as more appropriately measured in the objective nature of the physical or economic environment. For example in terms of climate, the quality of local shops and transport, employment opportunities, the availability of open spaces, and other leisure facilities and services. There are also more subjective definitions of place, its scenery and security, as experienced by the inhabitants, and perceived in its reputation by others which may affect morale, the quality of life and health (Curtis and Rees-Jones, 1998; G attrell \& al., 2000). Curtis and Rees-Jones (1998) suggest a conceptual map to help understand the relationship between area and health experience by 
describing a set of overlapping landscapes: ecological (e.g. industrial pollution); materialist (e.g. the quality of the housing stock); consumption (e.g. lack of public transport); and therapeutic (e.g. the degree of social cohesion). The classical policy questions which can be addressed within this conceptual framework are those concerned with the effects on quality of life and health in those with moderate or low income of improvements in the provision of public goods and services (Bartley $\&$ al., 1998; Lynch \&al., 2000).

The literature on area differences in health has in fact highlighted a number of factors (Macintyre $\&$ al., 1993; Williams and Ecob, 1999) which might well be expected to affect women differently, and in some case more strongly, than men. The presence of adequate shops, services and transport and the security of the streets for example, might be more important for women. The nature of a 'healthy' local labour market, also, will be quite different for women. Large numbers of heavy, dirty and dangerous jobs such as mining create a trade off in health terms for men between income and health risk. A local economy with large numbers of clerical, sales and service jobs in contrast may leave a pool of 'unemployable' men at risk of all the accompanying health hazards while creating a situation in which women have greater employment prospects and thereby control over their living standards.

O ur investigation focuses on the relationship between women's ill health and their personal and local material circumstances. We apply multilevel modelling to the ONS Longitudinal Study (LS) to analyse self-reported limiting long-term illness. The LS is a 1\% linked sample of individuals from the 1971, 1981 and 1991 Censuses (Hattersley and Creeser, 1995) for England and Wales. The question on limiting longterm illness, new in the 1991 Census, asks whether the respondent had a long-term illness, health problem or handicap which limits her daily activities or the work she can do. The responses are referred to hereafter as LLTI. Interestingly, D ale (1993) notes that pre-census test on the LLTI correlated well with other data on GP consultancies and inpatient and outpatient visits to hospital. She argues that it provides the only nationally consistent indication of health service needs.

In this analysis geography is represented by a population hierarchy where local neighbourhoods coincide with the boundaries of electoral wards and larger areas are described by county district boundaries. This describes a three level hierarchy whereby individual women are grouped in wards within county districts. The variation in LLTI is par- 
titioned into three distinct components: individual variation between women living in wards; that between wards within larger county districts and finally the variation between county districts themselves. The variation between individuals and both levels of area is modelled by including characteristics drawn from the census which portray social composition at both the individual and area level. Inequalities in health between women are a subject of interest in their own right, but in addition, we compare the results with those obtained for men.

The first step in investigating the relationships between individuals, area and health is to see if we can explain the area differences entirely on the basis of the characteristics of the resident women alone. Sloggett $\&$ al. (1993) using mortality as an outcome first attempted to answer this question using the LS. The analysis involved ordinary (single level) regression, which combined individual characteristics and aggregated information on the area of residence at the individual level. This was the only technique available at the time. A subsequent comparison of single and multilevel analyses of LLTI using data from three decennial censuses by Gleave $\&$ al. (1999) showed very similar estimates of regression coefficients under both approaches. Multilevel modelling was able to quantify the variation left unexplained by individual attributes and measured characteristics of the area.

\section{Background}

Geographical variation in the mortality of both men and women, both between and within regions is well known (Britton \& al., 1990; Sloggett \& al., 1993). A health disadvantage to living in northern regions, 'the North-South divide', has long been noted (Shaper, 1984; Sloggett and Joshi, 1994; Ecob and Jones, 1998). Despite sharp, yet uneven, decline in national mortality rates since the 1980s (Phillimore \& al., 1994; D rever and Whitehead, 1997), Britain in the 1990s has the largest regional mortality differences in the postwar period (Shaw $\&$ al., 1999).

In 1991 for the first time, a British Census included a question on long-term illness, which limits the activities of the individual. The results have shown sharp regional differences in this measure, which largely parallel those for mortality but limiting long-term illness is more concentrated geographically than mortality (Langford and Bentham, 1996). By exploiting the spatial dimension in the LS we are in a posi- 
tion to reveal how far those women in poor health according to selfreports of LLTI are clustered in areas of high social deprivation and begin to explain why this might be.

These regional differences could be due to women with different personal histories and characteristics living in different areas: 'the compositional effect'. Alternatively, they could be due to a variety of 'contextual effects' as outlined above. What further insight does the literature provide about the relationship between health and deprivation?

There is a large literature on the identification and healthiness of 'deprived areas' (e.g. Britton \& al, 1990; Carstairs, 1995; Charlton, 1996). 'D eprivation' has usually been defined as some combination of variables measured in the census such as unemployment, low social class and poor quality or public rented housing. These indicators are often regarded as representing poverty, though they are not perfect proxies for low income. Townsend (1991) describes adverse effects on living standards and health of London's 'deprived neighbourhoods'. This implies that health variations would not be explained by individual characteristics alone, and that broader influences on health would be reflected in community-level factors. Macintrye $\&$ al. (1993) list ways in which areas may be more or less healthy than would be expected given the composition of their residents: physical features of the local environment (e.g. pollution, traffic); conditions at home/ work/ play (e.g. parks and gardens); the quality and accessibility of health and other services; activities in the neighbourhood such as crime or political activism; and the place's reputation. The latter may act to reinforce individual disadvantage. A further source of community health is the notion of social capital from 'feeling part of the community' (Mitchell \& al., 2000). In this study civic engagement had a positive independent influence on health.

The interplay of local context, composition of the individuals living in the area and the individual's own characteristics have been investigated in a variety of ways. Macintyre and colleagues (1993) conducted a qualitative study of contextual contrasts between two areas of G lasgow. Q uantitative approaches range from ecological studies of standardized mortality related to census-based indicators of deprivation (e.g. Eames \& al., 1993), including variables relating to neighbourhood socio-economic composition in a regression on individual characteristics (Sloggett and Joshi, 1994), and allowing interaction between individual and community-based variables (Blaxter, 1990). Multi- 
level modelling had previously been used to examine effects of area and area classifications (e.g. Congdon, 1995; Duncan \& al., 1993; Gould and Jones, 1996; Shouls \& al., 1996).

This paper applies multilevel modelling to individual data in the LS, the largest scale English and Welsh data source which enables ward level data to be confronted with data on individuals. Results using single-level regression analysis suggest that much of the variation in several health indicators (e.g. death, long-term illness and low birthweight), which is systematically associated with the 'deprivation' of the locality at previous censuses, can be statistically accounted for by the characteristics of the individuals living in each area (Sloggett and Joshi, 1998a and b). This suggests that if there are any contextual effects on health, they are not well detected by a crude uni-dimensional indicator of deprivation, although such deprivation measures are conveniently based on census evidence. Using census indicators, Charlton (1996) finds that rural wards appear 'healthy' whatever the level of deprivation. The degree of urbanization and of affluence are also an independent component of the contextual elements found, alongside important individual components, in variations between districts by Shouls \& al. (1996), using the Sample of Anonymised Records (SARs) from the 1991 Census as a data source (CMU, 1993; Marsh, 1993; Marsh and Teague, 1992). The individual component was less salient in the multilevel analysis, by Humphreys and Carr-Hill (1991), of the Health and Lifestyle Study, clustered in 396 wards.

In our parallel work, on men, we did a multilevel analysis on sample of 69,352 also aged between 16 and 45 in 1971 (Wiggins \& al., 1998). This revealed that the wide variations between districts in LLTI in 1991 were only partly explained by men's individual experience of unemployment, low social class and other disadvantages in 1971 and 1981. Further explanation was contributed by including the type of areas according to the ONS typology of districts (Wallace and Denham, 1996). We concluded that the experience of disadvantage over time affected the risk of reporting LLTI, but did not explain all of the geographical differences. Men with the same characteristics and work and migration histories report LLTI at different rates in different types of area. In this paper we ask 'How does geography come into the explanation of social variations in LLTI for women?'

The analysis for women moves forward from our previous multilevel exercises, in two important ways. Firstly, we extend our geographical hierarchy to include ward, as a proxy for neighbourhood, 
nested within county districts. Secondly, we typify the aggregate character of wards by using our own census-based scores. Districts are classified, using the ONS classification (Wallace and D enham, 1996), as in Wiggins \& al. (1998). We are well aware that wards and county districts are imperfect descriptions of neighbourhood and space, and that census-based indicators have their limitations as either physical or psychological descriptions of the context.

To avoid substantial data loss we have abandoned any individual social classification or history based on occupational classification. These are especially unsatisfactory for women who do not always report an occupation, and for whom any occupation that is reported may not be a good indicator of her usual living standards. Those occupations, which are recorded for women, do not distinguish well between different levels of skill (Rees, 1992; Sacker $\notin$ al., 2000). Furthermore, there are problems with identifying change of occupation over time, as classifications change (Blackwell, 1998). Instead, we follow the recommendation of Moser $\& \mathrm{al}$. (1988) and use access to a car and housing tenure over time as markers of individual circumstances. Arber (1991) suggests that such consumption measures may be equally or more revealing of a woman's class position than occupation, perhaps because they are resources that make a difference in a woman's everyday life. Macintyre $\&$ al. (1998) also suggest that they may not only be related to health because they are markers for income or psychological traits; they may also have some directly health promoting or damaging effects.

O ur approach is, first, to clarify whether geographical variation is any greater than one would expect on the basis of the characteristics of the resident women alone. If it is, the second step is to explore the extent to which our characterisation of areas plays a role in understanding differences in limiting long-term illness both at the local and district level. 


\section{Method}

\subsection{Data source and structure}

We took from the ONS-LS datafile 76,374 women aged between 16 and 45 in 1971 (and hence aged 36-65 in 1991 - a 30-year cohort) who had full census records at the three time points. This involved discarding $18 \%$ of women in this age group who were matched and traced into the LS in 1991 (when the LLTI question was first included) who were not also present in one or both previous censuses. In a minority of the cases the women are known to be immigrants (ca 5\%), but the main reason for omission is linkage failure, i.e. the women's records could not be matched into the LS or they were absent from the census. Linkage for this age group is at approximately average rates for the whole study (Hattersley and Creeser, 1995). They report in Chapter 5 overall backward linkage rates of 93\% from 1981 and 91\% for 1991. Typically linkage failure affects the younger adults more than those in later middle age. A further $2 \%$ of the 1991 sample were discarded because their census record contained missing data or they were enumerated as a visitor or in a communal establishment. Finally just under 1\% (707 cases) with permanent sickness in 1971 or 1981 were also excluded from the analysis, in order to avoid, as far as possible, results being unduly influenced by the high chance certain individuals had of reporting limiting long-term illness in 1991. We note the possibility that housewives who were in very poor health may not have been identified by these questions, which are linked to those on economic activity, and would remain in our sample. The sample was clustered into 9,359 electoral wards nested within 403 county districts. For our sample the average number of women included in a ward is 8 and 191 per county district.

\subsection{Limiting long-term illness}

The outcome variable in the analysis is LLTI as described above.

\subsection{Individual characteristics}

In an attempt to explain the level of women's reported LLTI a number of individual characteristics are included in the model: age, 
education, ethnicity, and three summary indicators combining 1971 to 1981 censuses to reflect material circumstances and migration. Car access and home ownership were as reported in 1971 and 1981 by the household. Intercensal migration was defined in terms of the woman's movement either within or between county districts. Finally, enumeration in the South-East in either 1971 or 1981 was used to account for any potential material benefits of residence in this region on individual circumstances (following Fielding, 1995). A summary table of individual-level variables is shown in Table 1.

Table 1

Individual level variables used in the analysis

\begin{tabular}{|c|c|}
\hline Variable & Categories \\
\hline Age in 1971 & Measured as continuous variable \\
\hline Education & $\begin{array}{l}\text { D egree holder in } 1971 \text { and/ or } 1981 \\
\text { Non degree holder }\end{array}$ \\
\hline Ever resident in the South-East & $\begin{array}{l}\text { Lived in South-E ast in } 1971 \text { or } 1981 \\
\text { Lived outside South-East in } 1971 \text { or } 1981\end{array}$ \\
\hline Ethnicity & $\begin{array}{l}\text { White } \\
\text { Non-white }\end{array}$ \\
\hline Car access in household & $\begin{array}{l}\text { No car in } 1971 \text { or } 1981 \\
\text { No car in 1971, car in } 1981 \\
\text { Car in 1971, car in } 1981\end{array}$ \\
\hline Housing tenure & $\begin{array}{l}\text { Non-owner in } 1971 \text { and } 1981 \\
\text { Non-owner in 1971, owner in } 1981 \\
\text { O wner in 1971, non-owner in } 1981 \\
\text { O wner in } 1971 \text { and } 1981\end{array}$ \\
\hline Migration 1971-1981 & $\begin{array}{l}\text { Same district } \\
\text { Different district, same county } \\
\text { Different county }\end{array}$ \\
\hline
\end{tabular}

The majority of these individual level variables are categorical. In the modelling results that follow estimates of the fixed effects of being a member of a particular category are given in contrast to a reference category which is always, and arbitrarily, the first named category in the table above. Age was centered on the average age of 29.9 years in 1971. 


\subsection{Ecological or geographical units of analysis}

The second and third level units used in the analysis are respectively, the 9,359 wards and 403 county districts from 1991. Wards were characterised by 5 principal component scores derived from our analysis of 37 variables from the Small Area Statistics. For convenience these components have been labelled as dqpivation (poverty versus affluence), area type (educated professionals (along with young children of school age) versus poorer manual families), demogaphic darader (young families versus an older mixed population), settlement (young single people, often in private rented and terraced housing versus middle aged and larger families), and confort (households with 2 or more cars, central heating (typically in rural locations) versus households with manual heads, a high proportion of working women and use of public transport). At the third level in the geographical hierarchy, county districts are described as belonging to one of twelve homogenous groups based on similarities derived from the 37 individual census items exactly as in Wallace and Denham (1996). The labels used in the ONS area classification and in our analysis are shown in Table 2 together with the number of districts in each group and the average percentage

Table 2

Average \% LLTI for women aged 36-65 years in 1991 reported by ONS district level classification

\begin{tabular}{|l|c|c|c|}
\hline \multicolumn{1}{|c|}{ Area classification } & Number of districts & \% total districts & Mean \% LLTI \\
\hline Coalfields & 43 & 10.72 & 18.0 \\
Ports and industry & 15 & 3.74 & 18.4 \\
Inner London & 17 & 4.24 & 15.5 \\
Manufacturing & 23 & 5.74 & 15.3 \\
Resort and retirement & 24 & 5.99 & 12.6 \\
Mixed economies & 37 & 9.23 & 12.4 \\
Mixed urban and rural & 44 & 10.97 & 12.3 \\
Services and education & 18 & 4.49 & 10.6 \\
Coast and countryside & 66 & 16.46 & 10.2 \\
Growth & 25 & 6.23 & 9.7 \\
Most prosperous & 86 & 21.45 & 8.3 \\
Scotland & 3 & 0.75 & 7.8 \\
Totals/ overall LLTI & 401 & 100.00 & 12.9 \\
\hline
\end{tabular}


of LLTI reported for the age group used in our investigation. The extent to which any of these raw percentages are due to differences in the age composition of each cluster of districts by O NS area classification is taken into account at an individual level in subsequent modelling. Age standardized LLTI rates (not shown here) reveal very little difference in the rank ordering of the clusters by observed LLTI percentages.

The areas classified as 'Ports and industry' and 'Coalfields' have the highest levels of reported LLTI whereas 'Growth' and 'Most prosperous' areas (and districts labelled 'Scotland' with very few districts) have the lowest.

\subsection{Modelling strategy}

In the exploration of the interplay of person and place in influences on women's health, multilevel modelling allows both area and individual effects to be represented in a three level population hierarchy. Individual women at level-1 are nested within wards at level-2 and wards are nested within county districts at level-3. By separating out individual and area level characteristics it becomes possible to investigate how variables (our 5 principal component scores) defined at the ward level might affect the prevalence of limiting long-term illness over and above the contribution of a woman's characteristics. Similarly, the impact of the wider locality (county district) can be examined once the character of the ward and the individual resident's circumstances has been taken into account. All modelling was implemented by the software package MLwiN (G oldstein \&al., 1998).

Formally, the appropriate statistical model for a binary outcome is described as a logistic multilevel regression model (Goldstein, 1991). All model estimation was carried out using the default estimation procedure for non-linear models, namely marginal quasi-likelihood (MQL) followed by predictive quasi-likelihood (PQL) (Goldstein, 1995, Chapter 7). The fixed part of the model is defined by a linear function of both individual and area level explanatory variables. The random part of the model identifies three components of variance: between districts (level-3), between wards within districts (level-2 variance) and that between individual women within wards (the level-1 variance). The inclusion of area level characteristics in the model is equivalent to attempting to model any between-area differences as identified in 
terms of local or district effects. These area characteristics have been described above.

As age is expected a priori to be a predictor of LLTI status, it has to be included in any model. This simple model is referred to as our base model. It includes a quadratic term for age simply as a conventional device to improve statistical fit. This base model provides estimates of the two variance component estimates for ward differences within districts and between district differences. In terms of our central research question then, our objective is first to see whether or not we can formally identify between-area differences and if so, to see if we can explain any such differences in terms of the characteristics of the individual women who reside there and then the nature of these areas (composition). In modelling terms we proceed sequentially. First, after fitting the base model, we include all individual characteristics in the model and then check, by means of backward elimination of each characteristic in turn, whether or not a statistically significant contribution is made to the model (based on the reduction in the log likelihood, Goldstein \& al., 1998, p. 32). For the remaining variables we next test for the presence of interactions at the individual level. The resulting model is described as our inteim1 model (if you prefer, a 'reduced main effects and interactions' model). A second interim model is then fitted by attempting to explain any remaining ward level differences (inteim2) by including ward scores at level-2. Finally, the level-3 ONS area classification is included as a dummy variable to reduce any area level variance at the district level. This results in our final model. The results for all three models are presented in Table 3 . The interpretation of the modelling follows two strands. Firstly, the interpretation of the fixed part of the model and its ability to explain differences between areas. Fixed effects can be thought of as representing a typical or average effect of individual variables such as ethnicity, or the impact of the character of the area itself, on the risks of reporting LLTI across the whole sample. Secondly, district level residuals are mapped at each stage of modelling to reveal the extent to which any district has an excess of ill health or 'good' health. The small number of women observed in any ward mean that mapping ward level residuals would be unreliable. 
Table 3

Baseline, interim and final models for LLTI as a binary outcome for 76,374 women aged 16-45 in 1971 nested within 401 county districts in England and Wales (standard errors are given in parentheses)

\begin{tabular}{|c|c|c|c|c|}
\hline Terms & Base model & Interim model 1 & Interim model 2 & Final model \\
\hline $\begin{array}{l}\text { Fixed effects } \\
\text { Indidal (led-1) }\end{array}$ & & & & \\
\hline Constant & - $2.138(0.025)^{*}$ & $-1.825(0.086)^{*}$ & - $1.847(0.085)^{*}$ & $-1.636(0.097)^{*}$ \\
\hline Age & $0.072(0.002) *$ & $0.068(0.004)^{*}$ & $0.068(0.003)^{*}$ & $0.068(0.003)^{*}$ \\
\hline Age $^{2}$ & $-0.001(0.000) *$ & $-0.001(0.000)^{*}$ & $-0.001(0.000)^{*}$ & - $0.001(0.000)^{*}$ \\
\hline $\begin{array}{l}\text { Not in South-East in '81 } \\
\text { or ' } 91\end{array}$ & & $0.275(0.033)^{*}$ & $0.118(0.031)^{*}$ & $0.092(0.035) *$ \\
\hline No degree & & $0.371(0.074)^{*}$ & $0.315(0.075)^{*}$ & $0.313(0.075)^{*}$ \\
\hline Non-white & & $0.683(0.066)^{*}$ & $0.597(0.067)^{*}$ & $0.609(0.068)^{*}$ \\
\hline Cars (linear effect) & & $-0.204(0.011)^{*}$ & - $0.172(0.011)^{*}$ & $-0.170(0.011)^{*}$ \\
\hline $\begin{array}{l}\text { O wner occupier in '71 } \\
\text { and ' } 81\end{array}$ & & $-0.436(0.025)^{*}$ & $-0.357(0.026)^{*}$ & $-0.363(0.026)^{*}$ \\
\hline Interation & & & & \\
\hline Cars* Age & & $0.004(0.001)^{*}$ & $0.004(0.001)^{*}$ & $0.004(0.001)^{*}$ \\
\hline Ward(led-2) & & & & \\
\hline Poverty/ affluence score & & & $0.185(0.012)^{*}$ & $0.158(0.014)^{*}$ \\
\hline Area type score & & & - $0.092(0.013)^{*}$ & $-0.086(0.014)^{*}$ \\
\hline D emographic score & & & $0.034(0.013)^{*}$ & $0.037(0.014)^{*}$ \\
\hline Caunty distrid(lede-3) & & & & \\
\hline 'Scotland' & & & & - $0.769(0.303)^{*}$ \\
\hline Coastal & & & & - $0.280(0.060)^{*}$ \\
\hline Mixed urban and rural & & & & - $0.183(0.057)^{*}$ \\
\hline Growth & & & & $-0.240(0.055)^{*}$ \\
\hline Most prosperous & & & & - $0.285(0.082 *$ \\
\hline Services and education & & & & $-0.230(0.079)^{*}$ \\
\hline Resort and retirement & & & & $-0.115(0.076)^{*}$ \\
\hline Mixed economies & & & & $-0.249(0.060)^{*}$ \\
\hline Manufacturing & & & & $-0.125(0.059)^{*}$ \\
\hline Ports and industry & & & & $-0.136(0.059)^{*}$ \\
\hline Inner London & & & & $-0.221(0.079)^{*}$ \\
\hline Random effects & & & & \\
\hline Individual & 1.0 & 1.0 & 1.0 & 1.0 \\
\hline Ward & $0.096(0.017)$ & $0.036(0.015)$ & $0.021(0.014)$ & $0.018(0.014)$ \\
\hline County district & $0.119(0.013)$ & $0.049(0.008)$ & $0.011(0.04)$ & $0.009(0.004)$ \\
\hline Log likelihood & $30,757.8$ & $27,529.1$ & $26,641.7$ & $26,718.4$ \\
\hline
\end{tabular}

* Significantly different from zero at 95\% confidence. 


\section{Results}

\subsection{The interplay of individual and area level differences}

The estimates for fixed and random effects are given for each of the four stages of modelling in Table 3. The models are labelled base where age terms are the only individual characteristics included in the model; inteim 1 which includes individual characteristics (or reduced and relevant interaction terms) in addition to the age terms; inteim2 which begins to model area variation by including ward scores at level2; and fourthly, the final model completes the list with a categorical variable to describe the classification of the county district at level-3.

\subsection{Random effects}

Once we take account of a woman's age there are still differences between areas at both the ward and district levels. These estimates of area differences are variances of the estimated residual terms associated at each level. Here a level-2 variance of 0.096 for ward differences and a level-3 variance of 0.119 for districts, which are both statistically significant. In terms of our research question the challenge now is to see to what extent the inclusion of further terms, first about the woman and then about the localities, can explain these differences.

The inclusion of individual level characteristics at level-1 reduces the variance component at level-2 by almost two-thirds (a reduction of level-2 variance to 0.036 in interim model 1 ) as well as marking a dramatic reduction in the level-3 variance (by $59 \%$ to 0.049 ). Thus area differences at both the ward and district levels decrease convincingly once we take account of the characteristics of the women who make up the local populations. We will return to this observation in our analysis of district level residuals below, and to the individual predictors of women's health as described below. What further gains are there in the reduction of area differences if we now explore the impact of including the ward characteristics? Of the original 5 ward scores described earlier only three achieve any significance in the model. The addition of the ward scores in our interim model 2 achieves a successive reduction in the variance at both levels ( $42 \%$ to 0.021 for wards and $78 \%$ for county districts from 0.049 to 0.011 ). For the final model, which includes the ONS classification, we hardly see any further variance reduction. 


\subsection{Fixed effects}

Women's individual circumstances provide an important explanation of between area differences. The base model confirms a positive relationship between a woman's age and her probability of reporting a LLTI. The age quadratic term suggests stronger effects as age 65 approaches. Being non-white, without a degree (the only level of qualifications distinguished in the census), and not recorded as residing in the South-East, all contribute to increased risk of women reporting LLTI. Further, being without access to a car in '71 and ' 81 and/ or not being in owner occupancy for these time points also increases this risk. In Table 3 car access is reported as a linear effect. Thus the categories presented in Table 1 for car access can be read as an arithmetic scale from 0 to 3 . Housing tenure is reported as a dichotomous variable as the fixed effects estimates for categories distinguishing between different states of owner occupancy in 1971 or 1981 were not very different. The migration history variable was non-significant and it is not included in Table 3. The only significant interaction term to remain at the individual level was the joint effect of car access and age. It could well be that car access for older women becomes a necessity as a result of their health status. At an area level the nature of the immediate locality has an effect on the risk attributed to individual circumstance. Notably, living in a poor ward and/ or a ward where there is a preponderance of young families increases risk of poor health over and above a woman's characteristics. Being in a ward where there are a large number of educated families with young children will reduce that health risk for a woman. At a district level, being in any district other than a (former) Coalfield (the reference category) reduces individual risk. If anything, living in a district classified as a Resort and Retirement, Manufacturing or Port and Industry puts women closest to those with similar circumstances living in the Coalfields. This group stands in contrast to those living in districts described as 'Most prosperous' or 'G rowth areas'. However, it must be noted that whilst the district classification produces a fine tune on individual health risk it does not provide much by way of further explanation of between-area differences. The locality as described by the ward has a greater impact.

Allowing the fixed effects to vary within areas revealed no evi-

dence of any differential effects. O ur interpretation of the fixed part of the model is, therefore, reliable across different types of area. 


\subsection{Residual analysis to confirm our model interpretation}

This section replicates an analysis of district level residuals reported for men (Wiggins $\&$ al., 1998). Any examination of ward level residuals was ruled out, as each estimate would only be based on a few women (typically <10). Figure 1 maps the distribution of \%LLTI at a district level for women prior to any analysis. A 'North-South divide' line has been imposed on the maps following Sloggett and Joshi (1994). There are more 'pockets' or concentrations of higher levels of reported LLTI in the North compared to the South but there is not a clear divide. There are notable concentrations of high \%LLTI in districts located in Inner London, the South-West and the Isle of Wight.

An exploration of district level residuals enables us to examine what happens to the pattern of outliers as we systematically take account of information about the characteristics of women, their neighbourhoods and surrounding districts. A district level residual marks out the extent to which any excess or deficit of reported LLTI is observed at each stage of the modelling. A residual, which is described as having more reported LLTI than is predicted by multilevel regression, is an 'unhealthy' district. Whereas a residual, which has less reported LLTI than is predicted by the model, will convey the opposite 'healthy' effect of area. Residual plots are presented in Figures 2 and 3 below. Any residual, which is not plotted, simply includes zero in their 95\% confidence intervals.

Taking account of the age distribution of women (our base model) explains a lot of the district level variation in rates of reported LLTI. Those districts that remain as outliers throw the North-South divide into sharp focus. Only two districts in the South (one Inner London Borough and one area on the outskirts of West of London in Berkshire) report higher levels of expected LLTI, whereas the majority of excess levels of reported LLTI are north of the divide. Indeed, it is only in the South-East and South-West that we see health benefits. How does the picture change as we take account of women's individual circumstances?

Firstly, the number of significant residuals is reduced considerably. O ur account of individual circumstances has done a lot to explain healthy area effects at the district level. The persistent unhealthy districts remain in parts of the North West, North and East and South Wales. A solitary healthy district stands out in the South (an outer 


\section{Figure 1}

\% LLTI for LS women aged 36-65 years in 1991 by county district

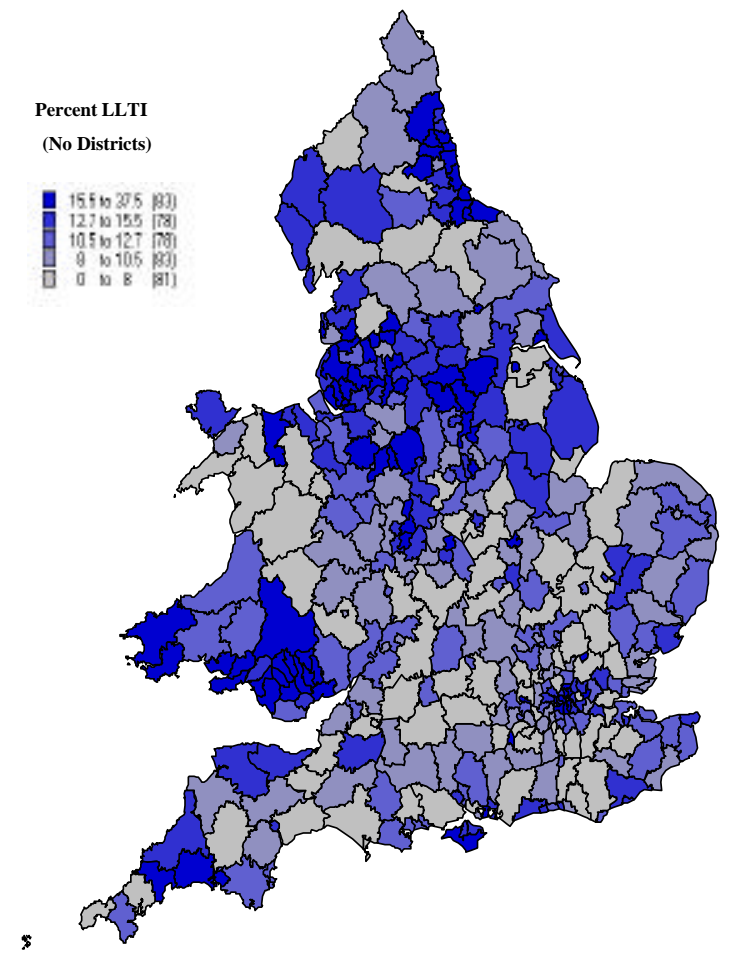


Figure 2

O utlier county district residuals for base model for LS women aged 36-65 years in 1991

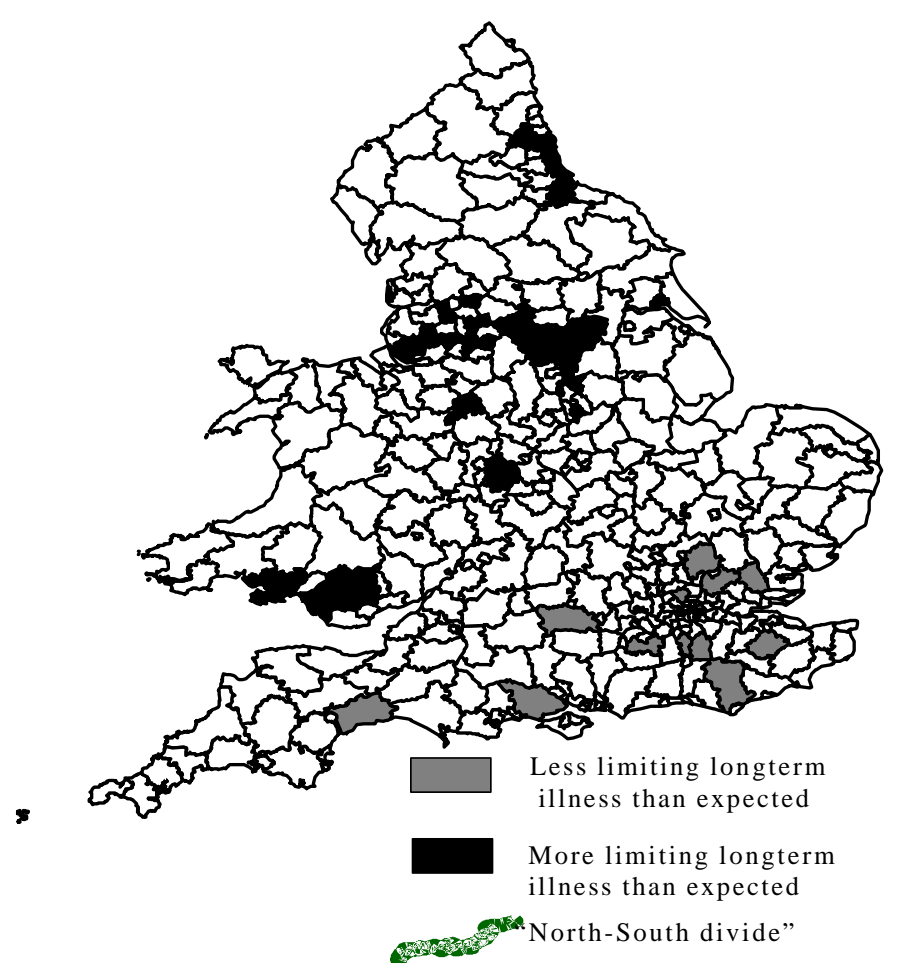




\section{Figure 3}

O utlier county district residuals for interim model 1 for LS women aged 36-65 years in 1991

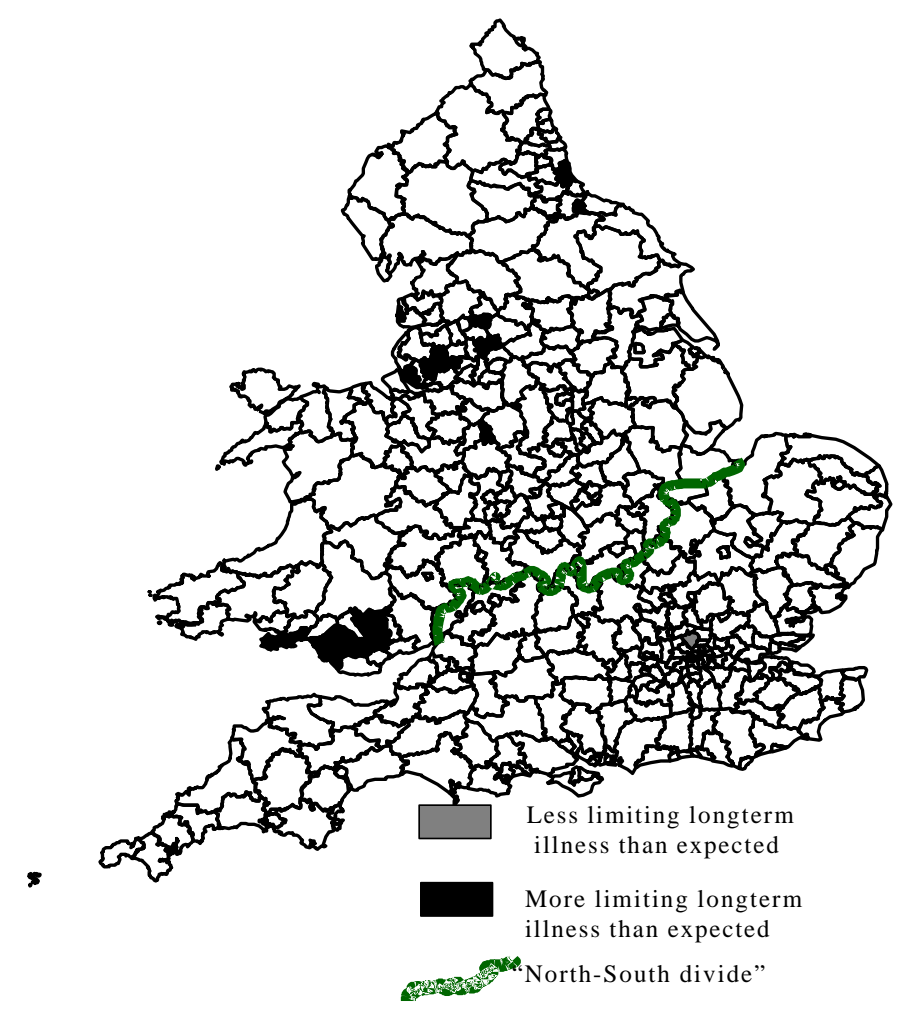


London Borough). O nce we introduce ward scores to characterise the neighbourhoods into the model these disparities largely disappear from the map. Providing further confirmation that spatial differences in reported LLTI for women can be largely accounted for by taking account of individual and local circumstance. Thus the scope for providing more visual displays of residuals ends with interim model 1. Whilst broader regional differences do affect the overall risk for the individual they do not add very much in terms of explaining the area differences reported in the raw data. Finally, the value of the log likelihood reported in Table 3 suggests that we are not strictly seeing a steady improvement in statistical fit beyond interim model 2. If anything the values are broadly similar between interim model 2 and the final model.

\section{Discussion}

For the first time this century in England and Wales with the inclusion of a question of limiting long-term illness in the 1991 Census it has been possible to observe the pattern of geographical variations in LLTI (Charlton and Wallace, 1994).

We have been able to pioneer the multilevel analysis of individual records in the ONS-LS. Earlier work (e.g. Congdon, 1995; D uncan \& al., 1993; Shouls \& al., 1996) has emphasised the importance of multilevel framework to better understand geographical variations in LLTI. Despite differences in the degrees of geographical clustering and coverage our findings are in broad agreement. Gould and Jones (1996) conclude that the variations between SAR areas remain substantial even when individual characteristics are taken into account. Unlike Congdon (1995) and Shouls \& al. (1996) they did not attempt to model or explain between-place variation. Shouls \& al. (1996) provide evidence of a stronger ecological effect for men than for women as well as for the interaction between individual and area level characteristics. From their interpretation it would appear that the differences between more and less deprived individuals are marked in affluent areas, rather than in more deprived areas. In future work we plan to explore similar interactions to better understand the interplay between individual and area level characteristics.

We have found that cars and home ownership were useful markers of social and material advantage apparently protecting against the 
risk of reporting LLTI. Migration into or living in the South-East region appeared beneficial, but otherwise there was not much effect of moving home. After also adjusting for a woman's individual circumstances (education and ethnicity), county district differences persist. It appears that almost all of the remaining area differences are explained by the social profile of wards in these areas. Whilst living in a (former) Coalfield does increase the individual health risk it does less in terms of accounting for area differences. This represents a notable difference in the finding for men (Wiggins \& al., 1999), where the O NS classification reduced the district level variance by nearly a half once ward scores were added to the model. For women the equivalent relative reduction is less than a fifth (0.011 to 0.009). For men, the majority of county districts with a high level of unexplained reported rates of LLTI are largely classified as Coalfields (past or present). This suggests two possible interpretations. The first is that the health of men in these places was more directly affected by the mining and heavy industrial activity because they were more likely to have been involved themselves in potentially harmful activities. However, we did find stronger geographical differentials for men in analyses which made some allowance for individual occupations.

Another interpretation, which could also complement the first, is that the reporting of limiting long-term illness is socially as well as biologically gendered. The concept presupposes a notion of a normal level of activity. In a context where local industrial change has removed many of the traditional employment opportunities for men, but less so for women, more men will find themselves unable to find employment. In other geographical contexts these men might otherwise be employed. Under these circumstances it is not clear whether supply or demand limits activity. The fusion of long-term unemployment and long-term ill health is compounded by the effect of morale and a sense of control (Wilkinson, 1996) on health and by specific gendered institutions in the British social insurance and support system.

The bureaucratic confirmation of a long-term sick status was much more likely to apply to men than to women. The term 'unemployment' is often associated with drawing benefit. There are two reasons why the benefit system tends not to treat married women and claimants in their own right. For most of this period, most married women opted out of National Insurance in their own right, relying on their husband's insurance. This option started to be phased out in 
1977. Even after that, married women could not make claims for means tested benefits except as a couple. D uring the 1980s the benefit system started to treat many (particularly male) claimants in their 50s and 60s as invalidity pensioners rather than unemployed. As women's perceptions of what they would normally be expected to do would cover domestic work and different sorts of employment from men's, there is a limit to which we can make direct pronouncements on gender differences in the individual propensity to report LLTI. We generally find more variability in LLTI for men at the district, or local labour market level than women. By the 1980s geographical variations in women's employment participation in Britain had become relatively minor, but traditionally (i.e. up to the 1970s) it had tended to be low [in the regions] where men's long-term illness tended to be high, particularly districts associated with mining and heavy industry. This applies particularly to South Wales, but a notable exception is the high female employment in the textile towns of the North-West (see Joshi and Hinde, 1993; Ward and Dale, 1991; Joshi, 1984). Thus if areas with the highest levels of reported male LLTI were also (to some extent) areas with the greatest differences in the gender division of paid labour, and of lifestyle, this could give rise to the differential geographical patterning by gender. We cannot however exclude the possibility that what we are seeing is a gender difference in a set of reactions to industrial decline. For men, in the affected labour markets, this is more manifest as the reporting of limiting long-term illness than it is for women. We can draw support for there being economic influences on reporting from our other analyses on current morbidity reported in survey data (Mitchell $\notin a l ., 2000)$.

\section{Conclusion}

The use of multilevel modelling has enabled us to analyse the risks of women aged 16-45 years in 1971 reporting LLTI in 1991 in a framework that divides area variation into two distinct components: that between localities (wards) within county districts and that between districts themselves. The modelling recognises the clustering of women's residential location by defining a population hierarchy based on administrative boundaries. These areas convey the role of geography, and the resulting social and economic characterisation of areas, in explaining illness reporting. In particular, any evidence for a 'North- 
South divide' in reported LLTI for women can be largely explained by the variables measuring characteristics of individuals and wards, which we have been able to include.

Blane $\&$ al. (1996) suggest that illness behaviour is shaped by the social environment and reflects the impact of disease on the ability to carry out social roles. What we have been able to show for women, as well as men, is that a set of variables reflecting material circumstances at the individual level: car access and home ownership, education, ethnicity and observation in the South-East help to explain the regional variation in reported illness, but not completely. Prevalence of LLTI also varies between localities defined by their social profile, even for women with similar individual characteristics. Most important is the influential role of aggregated ward characteristics for women's health over and above these individual similarities. Characteristics of the local economy, which do relate to variations in men's reported illness are less relevant to women. Where a woman lives matters much more in terms of her local neighbourhood than the wider socio-economic landscape.

\section{Acknowledgements}

This paper forms part of the programme of work of the ESRC Health Inequalities Programme: Dimensions of Health Over Persons, Time and Place (G rant No. L12851012). The authors also gratefully acknowledge the permission of the ONS to access the Longitudinal Study, and their assistance with initiating the use of multilevel modelling on their computers.

\section{References}

ARBER, S. (1991), "Class, paid employment and family roles: Making sense of structural disadvantage, gender and health status", Social Saience and Meediane, vol. 32, p. 425-436.

ARBER, S. (1997), "Comparing inequalities in women's and men's health: Britain in the 1990s", Soial SaiereandMediane vol. 44, p. 773-787.

ARBER, S. (2000), "Conceptual frameworks for studying women's health", Paper presented to the CICRED seminar on Soial and Economic Patteming of Health amongWomen, January, Tunis. 
Bartley, M., Blane, D., and Davey-Smith, G. (1998), "Beyond the Black Report", in: M. Bartley, D. Blane, and G. D avey-Smith, eds., TheSocidogy of Helth Inequality, O xford, Blackwells.

BlACKWELL, L. (1998), Ocaupational Sex Segegation and Part-TimeWork in Modem Bitain Ph.D. thesis, City University, London, U.K.

Blane, D., Power, C., and BARTLey, M. (1996), "Illness behaviour and the measurement of class differentials in morbidity", Jaumal of the Royal Statistical Socidy. SeiesA General, vol. 159, p. 77-92.

BlaXter, M. (1990), Health andLifestyles London, Tavistock/ Routledge.

Britton, M., Fox, A.J., Goldblatt, P., Jones, D.R., and Rosato, M. (1990), "The influence of socio-economic and environmental factors on geographical variation in mortality", in: MatalityandGeography, DS 9 OPCS, HMSO .

CARSTAIRS, V. (1995), "D eprivation indices: Their interpretation and use in relation to health", Jaumal of Epidemidogy andCommnityHelth vol. 49 (supp. 2), p. S3-S8.

Charlton, J. (1996), "Which areas are healthiest?", Population Trends vol. 83, p. 1724.

Charlton, J., and Wallace, M. (1994), "Long-term illness: Results from the 1991 Census", Population Trends vol. 25, p. 18-25.

CMU (1993), A User Guideto theSARs (2nd ed.), Census Microdata Unit, Faculty of Economic and Social Studies, University of Manchester.

Congdon, P. (1995), "The impact of area context on long-term illness and premature mortality: An illustration of multi-level analysis", Regional Studies vol. 29, no. 4, p. 327-344.

CuRTIS, S., and ReEs-Jones, I. (1998), "Is there a place for geography in the analysis of health inequality", in: M. Bartley, D. Blane, and G. Davey-Smith, eds., TheSo adogy of Health Inequality, Oxford, Blackwells.

DALE, A. (1993), "The content of the 1991 Census: Change and continuity", in: A. D ale and C. Marsh, eds., The1991 Census Use's Guide, London, HMSO, p. 16-51.

Drever, F., and Whitehead, M. (1997), Inequalities in Helth 1997, London, HMSO.

DunCAN, C., Jones, K., and Moon, G. (1993), "D o places matter? A multilevel analysis of regional variations in health-related behaviour in Britain", Scaal Saiene and Mediaine, vol. 37, no. 6, p. 725-733.

EAmes, M., Ben-Shlomo, Y., and Marmot, M. (1993), "Social deprivation and premature mortality: Regional comparison across England", British Medical Jarnal, vol. 307, p. 1097-1102.

ECOB, R., and JONES, K. (1998), "Mortality variations in England and Wales between types of place: An analysis of the ONS Longitudinal Study", Soial Saiene and Mediane, vol. 47, no. 12, p. 2055-2066.

FIELDING, A. (1995), "Inter-regional migration and intra-generational social class mobility 1971-1991", in: M. Savage and T. Butler, eds., Socal Changeand theMiddeClasses London, UCL.

Gattrell, A., Thomas, C., Bennett, S., Bostack, L., Popay, J., Williams, G., and ShahtahmaseBI, S. (2000), "Understanding health inequalities: Locating people in geographical and social spaces", in: E. Graham, ed., Undestanding Health Inequalities O pen University Press, Chapter 10.

Gleave, S., Bartley, M., and WigGins, R.D. (1998), "Limiting long-term illness: A question of where you live or who you are? A multilevel analysis of the 1971- 
1991 O NS Longitudinal Study", Longitudinal Studies WorkingPaper 77, Social Statistics Research Unit, City University, London.

Gleave, S., Wiggins, R.D., Joshi, H., and Lynch, K. (1999), "Identifying area effects: A comparison of single and multilevel models", in: P. Boyle, S. Curtis, A. Gattrell, E. Graham and E. Moore, eds., The Geogaphy of Heelth Inequalities in the Dexdoped Wordd Ashgate Press. Also available as LS Working Paper no. 79, The Centre for Longitudinal Studies, The Institute of Education, London.

Gold STEIN, H. (1991), "Nonlinear multilevel models: With an application to discrete response data", Biommrika, vol. 78, p. 45.

Gold STEIN, H. (1995), Multiled Statistical Modds(2nd ed.), London, Edward Amold, New York, Halstead Press.

Gold stein, H., Rasbash, J., Plewis, I., Draper, D., Browne, W., Yang, M., Woodhouse, G., and Healy, M. (1998), A Use's Guide to MLwìN, Multilevel Models Project, Institute of Education, University of London.

Gould, M., and JoNES, K. (1996), "Analyzing perceived limiting long-term illness using UK census microdata", Social SäereandMediane vol. 42, p. 857-869.

Hattersley, L., and Creeser, R. (1995), Longudinal Study 1971-1991: Histary, Organisation and Quality of Data, London, HMSO .

HumphreYs, K., and CARR-Hill, R. (1991), "Area variations in health outcomes: Artefact or ecology?" Intemational Jaumal of Epidamidogy, vol. 20, no. 1, p. 251258.

Jo SHI, H.E. (1984), Wonen's Participation in Paid Wokk: Further Analysis of the Women and Employment Survey, D epartment of Employment Research Paper, no. 45, London.

JoSHI, H.E., and HiNDE, P.R.A. (1993), "Employment after childbearing: Cohort study evidence", Europen Soadogical Review vol. 9, p. 203-227.

LANGFORD, I.H., and BENTHAM, G. (1996), "Regional variations in mortality rates in England and Wales, an analysis using multi-level modelling", Soial Saenceand Mediane, vol. 42, p. 897-908.

LynCH, J., D Ue, P., MunTANER, C., and Davey-Smith, G. (2000), "Social capital is it a good investment strategy for public health?" Jamal of Epidamidogy andCom muity Helth vol. 54, p. 404-408.

MACINTYRE, S., and HUNT, K. (1997), "Socio-economic position, gender and health. How do they interact?" Jaumal of Helth Psyddog, vol. 2, p. 315-334.

Macintyre, S., Maciver, S., and Sooman, A. (1993), "Area, class and health: Should we be focusing on places or people?" Jaumal of Sodal Pdigy, vol. 22, no. 2, p. 213-234.

Macintyre, S., Ellaway, A., Der, G., Ford, G., and Hunt, K. (1998), "Do housing tenure and car access predict health because they are simply markers of income or self esteem? A Scottish study", Jaumal of Epidemidogy and Commnity Health vol. 52, p. 657-664.

MARSH, C. (1993), "The sample of anonymised records", in: A. Dale and C. Marsh, eds., 1991 Census Use's Guide, London, HMSO, p. 295-311.

MARSH, C., and TEAGUE, A. (1992), "Samples of anonymised records from the 1991 Census", Population Trends, vol. 69, p. 17-23.

Mitchell, R., Gleave, S., Bartley, M., Wiggins, R.D., and Joshi, H. (2000), "D o attitude and area influence health? A multilevel approach to health inequalities", Health andPlace, vol. 6, p. 67-79. 
Moser, K., Pugh, H., and Gold BlatT, P. (1988), "Inequalities in women's health: Developing an alternative approach", British Medical Jamal, vol. 30, no. 296, p. 1221-1224.

Phillimore, P., Beattie, A., and Townsend, P. (1994), "Widening inequality of health: Northem England 1981-1991", British Meeical Jamal, vol. 308, p. 11251128.

REES, T. (1992), Wonen and theLabour Marke, London, Routledge.

Reijneveld, S.A., and Schene, A.H. (1998), "Higher prevalence of mental disorders in socioeconomically deprived urban areas in the Netherlands: Community or personal disadvantage?" Joumal of Epidamidogy and Commnity Helth vol. 52, p. 2-7.

RoBINSON, W.S. (1950), "Ecological correlations and behaviour of individuals", Ameican Soidogial Reiiew vol. 15, p. 351-357.

Sacker, A., FirTh, D., FitzPatrick, R., LynCh, K., and Bartley, M. (2000), "Comparing health inequality in men and women: A prospective study of mortality 1986-96", British Medical Jaumal, vol. 320, no. 7245, p. 1303-1307.

SHAPER, A. (1984), "G eographic variations in cardiovascular mortality in G reat Britain", Bitish Medical Bullein vol. 40, no. 4, p. 366-373.

ShaW, M., D ORLING, D., GoRD ON, D., and D AVEY-SMith, G. (1999), TheWidening Gap. Helth Inequalities and Pdioy in Bitain Studies in poverty, inequality and social exclusion, The Policy Press, Bristol.

Shouls, A., CongD ON, P., and CuRTIS, S. (1996), "Modeling inequality in reported long-term illness: Combining individual and area characteristics", Jamal of Epderidogy and CommuityHealth vol. 50, no. 3, p. 366-376.

SlogGeTT, A., and JosHI, H. (1994), "Higher mortality in deprived areas: community or personal disadvantage?" BritishMedical Jaumal, vol. 309, p. 1470-1474.

SlogGETT, A., and JoSHI, H. (1998a), "Indicators of deprivation in people and places: longitudinal perspectives", Envirommet and Plaming A, vol. 30, p. 10551076.

SlogGETT, A., and Jo SHI, H. (1998b), "D eprivation indicators as predictors of life events 1981-1992 based on the UK ONS longitudinal study", Jamal of Epidemdogy and Commuity Helth vol. 52, no. 4, p. 228-233.

Sloggett, A., Clarke, L., Joshi, H., and Eames, M. (1993), "Ecological factors and individual factors in women's mortality in England", in: B. Zaba and J. Clarke, eds., Enmiromment and Population Change Liège, O rdina Publications, p. 393-410.

TownSEND, P. (1991), "Living standards and health in the inner cities", in: MacGregor and Pimlott, eds., Tadkling theInnerCities Oxford, Clarendon Press, p. 93126.

Wallace, M., and Denham, C. (1996), The ONS Classification of Loal and Helth Authorities of Great Britain HMSO, London.

WARD, C., and DALE, A. (1991), "Geographical variation in female labour force participation: An application of multi-level modelling", Regional Studies vol. 26, p. 243-255.

Wiggins, R.D ., Bartley, M., Gleave, S., Jo Shi, H., Lynch, K., and Mitchell, R. (1998), "Limiting long-term illness: A question of where you live or who you are? A multilevel analysis of the 1971-1981 O NS longitudinal study", Risk, DeisionandPdigy, vol. 3, no. 3, p. 181-198. 
Wiggins, R.D, Bartley, M., Gleave, S., Joshi, H., and Lynch, K. (1999), "Health, area and the individual: A three-level analysis of the 1971-1991 ONS Longitudinal Study", BSPS Conferemepresentation.

Williams, R., and ECOB, R. (1999), "Regional mortality in the Irish in Britain: Findings from the ONS Longitudinal Study", Soidogy of Health and Illness vol. 21, p. 344-367.

WILKINSO N, R.G . (1996), Unhelthy Socieies TheAfflidions of Inequality, London, Routledge. 